$\angle$ Research Square

Preprints are preliminary reports that have not undergone peer review.

They should not be considered conclusive, used to inform clinical practice,

or referenced by the media as validated information.

\title{
Plant Microrna Potential in Targeting COVID-19 Genome Offering Efficient Antiviral Mirna-based Therapies
}

Behzad Hajieghrari ( $\sim$ bheghrari@yahoo.com )

Jahrom University https://orcid.org/0000-0002-7470-046X

Sara Rahmanian-Koshkaki

Shiraz University of Medical Sciences

\section{Research Article}

Keywords: Plant-derived miRNA, COVID-19, 3'-UTR, Translational repression, Antiviral miRNA-based therapy

Posted Date: September 25th, 2021

DOI: https://doi.org/10.21203/rs.3.rs-935657/v1

License: (c) (1) This work is licensed under a Creative Commons Attribution 4.0 International License. Read Full License 


\section{Abstract}

In 2019, the seventh member of the Coronaviridae named severe acute respiratory coronavirus II (or COVID-19) emerged in Wuhan, China. It could rapidly turn into a global pandemic. Therefore, searching for a natural/ novel therapy is urgently essential to prevent disease distribution. Based on the principle of crosskingdom interaction, plants are a candidate as a potential source of exogenous miRNAs that can efficiently affect the host cell gene expression by promote target mRNA degradation or repress protein translation, and, or virus RNA translation/replication. The possibility of taking up the diet-derived plantoriginated/artificially miRNA(s) in addition to their biological role in the host provides a pivotal clue for the study of synthesized/artificially expressed active therapeutic plant-originated miRNA(s) to promote antiviral activity. In this study, plant miRNAs, which can potentially interact with the COVID-19 genome within the 3'-UTR region and prompt antiviral function, were searched using bioinformatics approaches. RNAHybrid, RNA22, and STarMir miRNA/target detection tools were served for the possible plant miRNA/target recognition on the 3'-UTR flanking region of the COVID-19 genome by different algorithms. The RNAHybrid algorithm resulted in 63 plant miRNAs having hybridization energy with less or equal to $-25 \mathrm{kcal} / \mathrm{mol}$. They interact with diverse classes of miRNA/target binding patterns. However, each RNA22 and STarMir tools identified eight probable miRNA/target interaction candidates, in which pvumiR159a.2 and sbi-miR5387b detected by both the RNA22 and STarMir tools at the same position. For us, they are suitable plant-derived miRNA candidates, which have the great chance of targeting the COVID-19 genome in the 3'-UTR region in vitro to induce the virus degradation and translational repression and for antiviral miRNA-based therapies without any side effects in vivo.

\section{Introduction}

Coronavirus genus (Coronaviridae) has the largest single-stranded positive-sense RNA genome ( $30 \mathrm{~kb})$ among the human infected single-stranded RNA viruses (Pal et al. 2020). At the end of 2019, the seventh member of the Coronaviridae referred to as severe acute respiratory coronavirus II or COVID-19 emerged in Wuhan, China. It could rapidly turn into a global pandemic. COVID-19 genome has a 5'-cap structure and 3'-poly tail, like mRNAs. It includes at least six open reading frames (ORFs), which encode structurally (Nucleocapsid, membrane, Spike and small Envelop (E) glycoprotein) and non-structural proteins required for viral replication and pathogenesis (Abu-Izeneid et al. 2020; Canatan 2020). COVID-19 spread by person-to-person contact via virally loaded respiratory droplets and most probably in contact with eyes, nose, or mouth. It is a global life-threatening disease. Therefore, searching for a natural/ novel therapy is urgently essential to prevent disease distribution.

MicroRNAs (miRNAs) are a group of conserved small non-protein-coding endogenous single-stranded RNAs ( 18 to $24 \mathrm{nt})$, have a critical role as endogenous repressors of gene activity both transcriptionally and post-transcriptionally (Wahid et al. 2010; Ha and Kim 2018; Farrokhi and Hajieghrari 2020). They have a pivotal role in the principal cellular processes affecting diverse aspects of living organisms. miRNA biogenesis is well established and involves a series of intricate steps, which is being from the nucleus and completed in the cytoplasm (Please see O'Brien et al. 2018 for more detail). In the animal cell cytoplasm, miRNA is loaded to RNA induced silencing complex (RISC) and interacts with the $3^{\prime}$ untranslated region (3' UTR) of the mRNA coding sequences (CDS) physically by base pairing with nucleotides 2-7 of the loaded miRNA 5' end, which is called the seed sequence (Kehl et al. 2017).

In the case of positive-strand RNA virus, cellular miRNA may complementarily bind to the RNA virus miRNA-binding site(s) in 3'-UTR and coding region account translation and replication inhibition of the viral genome (Trobaugh and Klimstra 2017). However, It is evidenced those binding miRNAs to $5^{\prime} U T R$ cause the stabilization of the virus RNA and increasing the viral replication (Jopling et al. 2005; Shimakami et al. 2012). Direct miR-32 binding to primate foam retrovirus type I (PFV-1: a single-strand positive-sense RNA virus) genome in the 3'-UTR region inhibits virus replication (Lecellier et al. 2005). Also, hsa-miR 295-5p can bind to miRNA binding sites in the coding region of VP1 and VP3 proteins leading to translational repression and negatively regulates the genome replication in Enterovirus 71 (EV71) in the human neuronal cell line (Zheng et al. 2013). miRNAs can also bound the positive-sense RNA intermediated transcribed from negative-strand RNA viruses in their 3'-UTR or the coding region leading to the RNA degradation that may restrict virus replication (Song et al. 2010; Ingle et al. 2015; Khongnomnan et al. 2015). The host miRNA(s) are directly or indirectly involved in the regulation of antiviral pathways (Nguyen et al. 2018; Barbu et al. 2020; Abu-Izneid et al. 2021). In return, viruses have an impact on host miRNA expression patterns. Viruses are capable of regulating one or a few miRNAs, which beneficially for viral translation and replication. Also, many human viruses encode their miRNA(s). They modify the cell environment for its not only translation but also replication. Therefore, direct targeting of viral RNAs by the host cellular miRNA is more common. However, many of these interactions result in positive regulation of the viral cycle (Girardi et al. 2018), and adverse miRNA target sites within a viral genome have most likely been remove under the selection pressure during the virus-host co-evolutionary duration. The natural capacity of host cellular miRNA machinery indirect targeting of viral RNA can be beneficial to design an effective live attenuated vaccine against human viral infection by incorporating cell miRNA-mediated mRNA decay machinery.

It is also worth mentioning that plant-derived miRNAs can be transmitted from plants to mammals employ mammalian cell endogenous miRNA-involved machinery to regulate their target gene(s) (Zhang et al. 2012). Several growing bodies of evidence have also demonstrated that diverse plant-derived miRNAs can be found in the mammalian, including human serum and plasma, through dietary intake by passing from the gastrointestinal tract (Vaucheret and Chupeau 2012). Moreover, the mature sequences of plant-derived miRNAs have the potential of regulatory function after acquisition through specific diets, and food supplements may affect the biological process of another distantly related species. The other forms of miRNA, including pre-miRNA, doublestranded miRNA, and single-stranded DNA miRNA, have not cross-species regulatory abilities (Zhang et al. 2012; Samad et al. 2020). The 2'-0-methylated at 3' end and high GC content of mature miRNAs guarantee their survival in various environments like inside the gastrointestinal tract structurally (Ji and Chen 2012; Liang et al. 2013; Zhou et al. 2015) even after the food is cooked or boiled for decoction (Zhang et al. 2012). Several identified plant miRNAs complementary to human and domesticated animals are ideal candidates for dietary therapy approaches (Wang et al. 2018). For example, it evidenced that orally delivered plant miR159 can inhibit the growth of xenograft breast tumors in mice (Chin et al. 2016). Some but growing evidence accumulation reveal that some plant-derived miRNA sequences are base pair with the RNA virus's miRNA binding site complementarily. Such miRNAs have the potential to inhibit viral replication (Zhou et al. 2015). This research area deserves more attention in terms of mechanisms of action and to determine if there is therapeutic value to supplements or foods containing these specific miRNAs. 
According to our comprehensive literature search, positive-strand RNA viruses genome like COVID-19 mimic cellular mRNAs, and miRNA can bind to the viral RNA analogous to that of host mRNA. In this context, the exogenous plant-based miRNA(s), which does not exert a side effect(s) on any human genes, can bind the RNA virus's miRNA binding site. The binding sites may locate in both 5'UTR and 3'-UTR regions (). miRNA-RNA viral genome interactions can regulate its translation, replication, and altering its pathogenesis using the host cell RISC machinery (Trobaugh and Klimstra 2017). However, the coding region of viral proteins like spike protein (S-protein), angiotensin 35 converting enzyme 2 (ACE2), main protease (Mpro), and RNA-depended RNA polymerase (RdRp) can target by the exogenous plant-based miRNA(s) (Song et al. 2010; Zhang et al. 2012).

The exogenous miRNA-host RISC complex may bind to the virus target site leading to mRNA degradation, translational repression, and deadenylation (Catalanotto et al. 2016). Targeting the 3'-UTR region may trigger the virus RNA deadenylation leading to decapping, and in the initiation phase, inhibit capdepended translation. Without the 3' poly-A cap structure, the viral RNA fails to assume the circular conformation. Its translation process is ultimately depressed and degraded by the cytoplasmic 5'-to-3' exoribonucleases like XRN1 (Nagarajan et al. 2013). However, the plant-originated miRNA prediction has physical interaction with the appropriate target(s) is a challenge for computational pattern recognition. Especially, animal miRNA binding sites, because of low complementarity in the animal miRNA target site, its prediction is more complicated than plant miRNA binding target site prediction (Witkos et al. 2011). It encourages us to investigate a potent exogenous plant-based miRNA(s) vaccine or a therapeutic approach applicable to the patient who already contracted the infection.

In this study, we searched and analyzed the plant miRNAs using diverse miRNA/target prediction algorithms, which can potentially bind to the viral RNA genome within the 3 '-UTR region preventing the viral genome replication without any side and off target effects on the human protein-coding genes.

\section{Materials And Methods}

Herein, mature miRNA sequences from all plant species were obtained from miRBase (http://www.mirbase.org; release 21st of June 2014) and employed as the mature miRNA reference set. Also, the genome sequence for COVID-19 (NCBI Reference Sequence: NC_045512.2) and its annotated sequences were downloaded from gene bank (NCBI) in FASTA format and used as the target sequence set. To reduce the number of false positives and getting a more reliable result, potent antiviral plant-based miRNA were considered in the viral genome at 3'-UTR region by several target prediction programs. However, the presence of miRNA binding sites in the $5^{\prime} U T R$ and viral coding region of the genes has been already described in the scientific literature, searching the target sites within the viral RNA 3'-UTR region can increase the efficiency. Therefore, we only considered the miRNA binding site(s) prediction within the 3' UTR and ignored the site(s) in the $5^{\prime}$-UTR and, or coding regions.

Several miRNA/target detection tools develop in humans and other animals, which use distinct criteria and stringency to provide the best set of candidate target for a subset of miRNAs. They are divided into two main categories; established based on using conservation comparison or not. In this study, due to the phylogenetic distance between the miRNAs and the target, we did not employ the algorithms that use comparison criteria for predicting miRNA-mRNA interaction. Thus, we employ the algorithms, which use other parameters such as seed match, the free energy of binding, or site accessibility in the $3^{\prime}$-UTR that affect the miRNA binding. Initially, to predict plant miRNAs that hybridize to its target site in the 3'-UTR in an energetically most favorable way and having perfect helices in its 5'-end, the RNAhybrid (Kruger and Rehmsmeier 2006) was used. Thermodynamic in miRNA/mRNA duplex is one of the crucial features. It assesses by calculating the free energy $(\Delta G)$ of the putative binding. Thermodynamic stability that is considered by calculation the minimum free energy (MFE) or Gibb's free energy $(\Delta \mathrm{G})$ in miRNA/mRNA duplex tends to ensure stable targeting. However, the quality of free energy measurement is the key due to the empirical nature of the calculation and address to be a source of errors. It makes free energy is inaccurate or incomplete and cannot guarantee the existence of miRNA/mRNA interaction. For reducing false positives, the maximum free energy threshold did set to $25 \mathrm{Kcal} / \mathrm{mol}$.

In addition, the RNA22 tool (Miranda et al. 2006) served for the possible plant miRNA target recognition on the viral genome at the 3'-UTR region. RNA22 is a pattern-based algorithm and suitable tool for predicting putative microRNA binding site(s) that may not be conserved even in phylogenetically proximal organisms. The STarMir tool (Rennie et al. 2014) is another computational algorithm for predicting the potential miRNA-binding sites. It uses sequence, thermodynamic, and target structure features from crosslinking immunoprecipitation (CLIP) studies.

\section{Results}

Plant miRNAs usually perform perfect or near-perfect complementarity with their target sites (Hajieghrari et al. 2017). However, animal miRNAs often bind to their targets with imperfect complementarity (Hajieghrari et al. 2019). Therefore, in animals, the computational prediction of miRNA targets is much more complicated than in plants. The miRNA-target prediction algorithms often use base-pairing rule, evolutionary conservation, and, or thermodynamics of mRNA/miRNA duplexes. Some of them may use other features to improve prediction accuracy. Here, the RNAhybrid tool employed to determine the miRNAs, which hybridized to the best fitting part of the $3^{\prime}$-UTR sequence in terms of structure and free energy hybridization of the miRNA/the mRNA interaction. The RNAhybrid tool found all possible binding sites starting with the seed match in the 3'-UTR and picked them if the MFE were less than by the cut-off - 25 $\mathrm{kcal} / \mathrm{mol}$. There are 63 plant miRNAs identified as having hybridization energy with less or equal to $-25 \mathrm{kcal} / \mathrm{mol}$ (Table 1). For all predicted miRNA/mRNA hybrids, the RNAhybrid tool assigned a $P$-value of 1.000 between the human 3UTR sequence sets. Regions of strict Watson-Crick complementary pairs, mismatches, and bulges found in the miRNA/binging site. As can be seen, different classes of miRNA/target binding sites presented. Gma-miR4390, osamiR1424, gma-miR4389 have an adenine in position one and a strict Watson- Crick pairing in the seed position (2-7 positions) at the 5' end miRNA (the canonical 7mer-A1 site type). Pvu-miR159a.2, sbi-miR5387b, ptc-miR473b, ppt-miR898a, osa-miR5149 have a conservative adenine at opposite base 1, complete Watson-Crick pairing within the seed region, and additional Watson-Crick pairing at position 8 (the canonical 8-mer site type). We also found pabmiR482c, aly-miR862-5p, vvi-miR479, which target the 3'-UTR with a single nucleotide mismatch in the seed site (the non-canonical seed plus single mismatch; Steinkraus et al. 2016). Nevertheless, some predicted results did not show identified miRNA/target binding pattern. 
Page $4 / 17$ 
Table 1

Predicted target sites for plant miRNAs in the 3-UTR section of COVID-19 genome by the RNAhybrid tool in an energetically most favorable way. No G:U base pairs in the seed region were allowed.

\begin{tabular}{|c|c|c|c|c|c|}
\hline $\begin{array}{l}\text { miRNA name } \\
\text { (miRBase) }\end{array}$ & miRNA sequence & $\begin{array}{l}\text { Binding } \\
\text { start } \\
\text { position }\end{array}$ & $\begin{array}{l}\mathrm{MFE} \\
\mathrm{kcal} / \mathrm{mol}\end{array}$ & Seed Type & Target/miRNA alignment \\
\hline \multirow[t]{4}{*}{ pta-miR1315 } & \multirow[t]{4}{*}{ UGGAGGCCUGUCAGGUUCCCA } & \multirow[t]{4}{*}{26} & \multirow{4}{*}{$\begin{array}{l}-28.9 \\
\mathrm{kcal} / \mathrm{mol}\end{array}$} & \multirow[t]{4}{*}{-} & target 5' A GG A A A C 3' \\
\hline & & & & & GGGA ACUUGA AG GCC CCA \\
\hline & & & & & CCCU UGGACU UC CGG GGU \\
\hline & & & & & miRNA 3' A G A 5' \\
\hline \multirow[t]{4}{*}{ aly-miR3446 } & \multirow[t]{4}{*}{ CUCGGAAGCUAGACGUGUGGCAGG } & \multirow[t]{4}{*}{57} & \multirow{4}{*}{$\begin{array}{l}-29.8 \\
\mathrm{kcal} / \mathrm{mol}\end{array}$} & \multirow[t]{4}{*}{-} & target 5' A GAG G ACGA U 3' \\
\hline & & & & & CC GCCACGCG AGU UCGAG \\
\hline & & & & & GG CGGUGUGC UCG GGCUC \\
\hline & & & & & miRNA 3' A AGA AA 5' \\
\hline \multirow[t]{4}{*}{ osa-miR5509 } & \multirow[t]{4}{*}{ UAGGCAUUUUCUCUUGGCAUG } & \multirow[t]{4}{*}{96} & \multirow{4}{*}{$\begin{array}{l}-28.2 \\
\mathrm{kcal} / \mathrm{mol}\end{array}$} & \multirow{4}{*}{$\begin{array}{l}\text { Seed match form } 1-8 \text { allowing } 1 \\
\text { bit insertion seed match }\end{array}$} & target 5' A C U 3' \\
\hline & & & & & AUGCUAGG GAGAG UGCCUA \\
\hline & & & & & UACGGUUC CUUUU ACGGAU \\
\hline & & & & & miRNA 3' G U 5' \\
\hline \multirow[t]{4}{*}{ mtr-miR2613 } & \multirow[t]{4}{*}{ CGGUCGCCGGUGGUCAAUGGU } & \multirow[t]{4}{*}{56} & \multirow{4}{*}{$\begin{array}{l}-28.4 \\
\mathrm{kcal} / \mathrm{mol}\end{array}$} & \multirow[t]{4}{*}{-} & target 5' C A G AGUA A 3' \\
\hline & & & & & ACCG GGCCAC CGG CGAUCG \\
\hline & & & & & UGGU CUGGUG GCC GCUGGC \\
\hline & & & & & miRNA 3' AA 5' \\
\hline \multirow[t]{4}{*}{ gma-miR4390 } & \multirow[t]{4}{*}{ UCGUACUCGUCGGGUAUCGGGUAU } & \multirow[t]{4}{*}{57} & \multirow{4}{*}{$\begin{array}{l}-29.7 \\
\mathrm{kcal} / \mathrm{mol}\end{array}$} & \multirow[t]{4}{*}{$7 m e r-1 A$} & target 5' A G A G U 3' \\
\hline & & & & & CCGA GCC CG C GAGUACGA \\
\hline & & & & & GGCU UGG GC G CUCAUGCU \\
\hline & & & & & miRNA 3' UAUG A U 5' \\
\hline \multirow[t]{4}{*}{ gma-miR4416 } & \multirow[t]{4}{*}{ ACGGGUCGCUCUCACCUAGG } & \multirow[t]{4}{*}{99} & -30.0 & - & target 5' G U A 3' \\
\hline & & & & & CUAGG GAGAGC GCCU \\
\hline & & & & & GAUCC CUCUCG UGGG \\
\hline & & & & & miRNA 3' G A C CA 5' \\
\hline osa-miR2907a & GGCAGCCGAGCGAGGGCCUCGG & 57 & $\begin{array}{l}-30.6 \\
\mathrm{kcal} / \mathrm{mol}\end{array}$ & - & $\begin{array}{l}\text { target 5' A A GGAGUACGA A } \\
\text { GUACAGUGAACAA A } 3^{\prime}\end{array}$ \\
\hline & & & & & $\begin{array}{l}\text { CCGAGGCC CGC UCG GU } \\
\text { UGCU }\end{array}$ \\
\hline & & & & & $\begin{array}{l}\text { GGCUCCGG GCG AGC CG } \\
\text { ACGG }\end{array}$ \\
\hline & & & & & miRNA 3' GA 5' \\
\hline osa-miR2930 & UUCUCUUCUCUCGCGCGUGGCC & 61 & -30.6 & - & target 5' A UAC UC U 3' \\
\hline & & & KCais/TIUI & & GGCCACGCG GAG GA GAG \\
\hline & & & & & CCGGUGCGC CUC CU CUC \\
\hline & & & & & miRNA 3' G U U UU 5' \\
\hline mtr-miR5276 & AGGGGGAGCACCUUGCUGGGGCAU & 125 & $\begin{array}{l}-29.8 \\
\mathrm{kcal} / \mathrm{mol}\end{array}$ & - & $\begin{array}{l}\text { target 5' A AUGU } \\
\text { AAAUUAAUUUU UA A A 3' }\end{array}$ \\
\hline & & & & & $\begin{array}{l}\text { GCCCUA GUA AG GUGCU } \\
\text { UCCCC }\end{array}$ \\
\hline & & & & & $\begin{array}{l}\text { CGGGGU CGU UC CACGA } \\
\text { GGGGG }\end{array}$ \\
\hline & & & & & miRNA 3' UA A 5' \\
\hline
\end{tabular}




\begin{tabular}{|c|c|c|c|c|c|}
\hline $\begin{array}{l}\text { miRNA name } \\
\text { (miRBase) }\end{array}$ & miRNA sequence & $\begin{array}{l}\text { Binding } \\
\text { start } \\
\text { position }\end{array}$ & $\begin{array}{l}\mathrm{MFE} \\
\mathrm{kcal} / \mathrm{mol}\end{array}$ & Seed Type & Target/miRNA alignment \\
\hline \multirow[t]{4}{*}{ osa-miR1423b } & \multirow[t]{4}{*}{ CAACUACACGUUGGGCGCUCGA } & \multirow[t]{4}{*}{123} & \multirow{4}{*}{$\begin{array}{l}-28.1 \\
\mathrm{kcal} / \mathrm{mol}\end{array}$} & \multirow[t]{4}{*}{-} & target $5^{\prime}$ A A 3' \\
\hline & & & & & GAGC CCUAAUGUGUA \\
\hline & & & & & CUCG GGGUUGCACAU \\
\hline & & & & & miRNA 3' AG C CAAC 5' \\
\hline \multirow[t]{4}{*}{ osa-miR2925 } & \multirow[t]{4}{*}{ UGGCGGCCGCGGGCUUCGU } & \multirow[t]{4}{*}{58} & \multirow{4}{*}{$\begin{array}{l}-30.4 \\
\mathrm{kcal} / \mathrm{mol}\end{array}$} & \multirow[t]{4}{*}{-} & target 5' C A AGUA A A 3' \\
\hline & & & & & CGAGGCC CGCGG CG UCG \\
\hline & & & & & GCUUCGG GCGCC GC GGU \\
\hline & & & & & miRNA 3' U G 5'p \\
\hline \multirow[t]{4}{*}{$\begin{array}{l}\text { osa-miR1423- } \\
5 \text { p.2 }\end{array}$} & \multirow[t]{4}{*}{ AGGCAACUACACGUUGGGCGCUCG } & \multirow[t]{4}{*}{123} & \multirow[t]{4}{*}{$\begin{array}{l}-30.9 \\
\mathrm{kcal} / \mathrm{mol}\end{array}$} & \multirow[t]{4}{*}{-} & $\begin{array}{l}\text { target 5' A AAAAUUAAUUUU } \\
\text { AG A 3' }\end{array}$ \\
\hline & & & & & $\begin{array}{l}\text { GAGC CCUAAUGUGU AGU } \\
\text { UGCU }\end{array}$ \\
\hline & & & & & $\begin{array}{l}\text { CUCG GGGUUGCACA UCA } \\
\text { ACGG }\end{array}$ \\
\hline & & & & & miRNA 3' G C A 5' \\
\hline \multirow[t]{4}{*}{ gma-miR167i } & \multirow[t]{4}{*}{ UCAUGCUGGCAGCUUCAACUGGU } & \multirow[t]{4}{*}{98} & \multirow{4}{*}{$\begin{array}{l}-28.5 \\
\mathrm{kcal} / \mathrm{mol}\end{array}$} & \multirow[t]{4}{*}{-} & target 5' U GGA UA A 3' \\
\hline & & & & & GCUAG GAGCUGCC UAUGG \\
\hline & & & & & UGGUC UUCGACGG GUACU \\
\hline & & & & & miRNA 3' AAC UC 5' \\
\hline \multirow[t]{4}{*}{ gma-miR4370 } & \multirow[t]{4}{*}{ AGUAGACUCGUCCGAUUUUGCGUA } & \multirow[t]{4}{*}{65} & \multirow{4}{*}{$\begin{array}{l}-28.1 \\
\mathrm{kcal} / \mathrm{mol}\end{array}$} & \multirow[t]{4}{*}{-} & target 5' C A AU G A 3' \\
\hline & & & & & ACGCGGAGU CG CGAGU UAC \\
\hline & & & & & UGCGUUUUA GC GCUCA AUG \\
\hline & & & & & miRNA 3' A CU G A 5' \\
\hline \multirow[t]{4}{*}{ pvu-miR159a.2 } & \multirow[t]{4}{*}{ CUUCCAUAUCUGGGGAGCUUC } & \multirow[t]{4}{*}{106} & -28.3 & 8 mer & target 5' A G A 3' \\
\hline & & & & & GAGCU CCU AUAUGGAAG \\
\hline & & & & & UUCGA GGG UAUACCUUC \\
\hline & & & & & miRNA 3' C G UC 5' \\
\hline gma-miR398c & UGUGUUCUCAGGUCGCCCCUG & 24 & -25.5 & - & target $5^{\prime} \cup A A A C 3^{\prime}$ \\
\hline & & & & & UAGGG G GACUUGA GAGC CA \\
\hline & & & & & GUCCC C CUGGACU CUUG GU \\
\hline & & & & & miRNA 3' G U 5' \\
\hline cre-miR1145.1 & UUGGGGCCCAGCAGGUCCUGG & 99 & $\begin{array}{l}-27.9 \\
\mathrm{kcal} / \mathrm{mol}\end{array}$ & - & $\begin{array}{l}\text { target 5' G AGAG CUAUA } \\
\text { AAGA U 3' }\end{array}$ \\
\hline & & & & & $\begin{array}{l}\text { CUAGGG CUGC UGG } \\
\text { GCCCUAA }\end{array}$ \\
\hline & & & & & $\begin{array}{l}\text { GGUCCU GACG ACC } \\
\text { CGGGGUU }\end{array}$ \\
\hline & & & & & miRNA 3' G 5' \\
\hline ptc-miR319i & UUGGGCUGAAGGGAGCUCCC & 103 & $\begin{array}{l}-26.4 \\
\mathrm{kcal} / \mathrm{mol}\end{array}$ & - & $\begin{array}{l}\text { target 5' G A G AUAUGGAAG U } \\
3^{\prime}\end{array}$ \\
\hline & & & & & GG GAGCU CCU AGCCC \\
\hline & & & & & CC CUCGA GGA UCGGG \\
\hline & & & & & miRNA 3' G AG UU 5' \\
\hline
\end{tabular}




\begin{tabular}{|c|c|c|c|c|c|}
\hline $\begin{array}{l}\text { miRNA name } \\
\text { (miRBase) }\end{array}$ & miRNA sequence & $\begin{array}{l}\text { Binding } \\
\text { start } \\
\text { position }\end{array}$ & $\begin{array}{l}\mathrm{MFE} \\
\mathrm{kcal} / \mathrm{mol}\end{array}$ & Seed Type & Target/miRNA alignment \\
\hline \multirow[t]{4}{*}{ bdi-miR5165 } & \multirow[t]{4}{*}{ AUCUUGGGCUCUAGGUAGGUU } & \multirow[t]{4}{*}{106} & \multirow{4}{*}{$\begin{array}{l}-26.8 \\
\mathrm{kcal} / \mathrm{mol}\end{array}$} & \multirow[t]{4}{*}{-} & target 5' A G AUAUGGA U 3' \\
\hline & & & & & GA CUGCCU AGAGCCC \\
\hline & & & & & UU GAUGGA UCUCGGG \\
\hline & & & & & miRNA 3' G UUCUA 5' \\
\hline \multirow[t]{4}{*}{ sbi-miR5387b } & \multirow[t]{4}{*}{ CGUGGCUCUGACCGGUGCUAAAGG } & \multirow[t]{4}{*}{29} & \multirow{4}{*}{$\begin{array}{l}-25.4 \\
\mathrm{kcal} / \mathrm{mol}\end{array}$} & \multirow[t]{4}{*}{ 7mer-m8 } & target 5' G G U AA C 3' \\
\hline & & & & & AG ACU G AGAGCCAC \\
\hline & & & & & UC UGG C UCUCGGUG \\
\hline & & & & & miRNA 3' GGAAA G C AG C 5' \\
\hline \multirow[t]{4}{*}{ mtr-miR2659b } & \multirow[t]{4}{*}{ CCAUGGGUGCGACUUGGUAAG } & \multirow[t]{4}{*}{97} & \multirow{4}{*}{$\begin{array}{l}-25.3 \\
\mathrm{kcal} / \mathrm{mol}\end{array}$} & \multirow[t]{4}{*}{-} & target 5' A GAGA UG UAU A 3' \\
\hline & & & & & UGCUAGG GC CC AUGG \\
\hline & & & & & AUGGUUC CG GG UACC \\
\hline & & & & & miRNA 3' GA AG UG 5' \\
\hline \multirow[t]{4}{*}{ cme-miR390 } & \multirow[t]{4}{*}{ AAGCUCAGGAGGGAUAGCGCC } & \multirow[t]{4}{*}{153} & \multirow[t]{4}{*}{$\begin{array}{l}-26.0 \\
\mathrm{kcal} / \mathrm{mol}\end{array}$} & \multirow[t]{4}{*}{-} & $\begin{array}{l}\text { target 5' A A UGAUUUUAAU C } \\
3^{\prime}\end{array}$ \\
\hline & & & & & GUGCUAUCCC C UG AGCUU \\
\hline & & & & & CGCGAUAGGG G AC UCGAA \\
\hline & & & & & miRNA 3' C A G 5' \\
\hline \multirow{4}{*}{$\begin{array}{l}\text { osa-miR2867- } \\
3 p\end{array}$} & \multirow[t]{4}{*}{ CCAGGACGUGUGGGAUGGCA } & \multirow[t]{4}{*}{154} & \multirow{4}{*}{$\begin{array}{l}-26.6 \\
\mathrm{kcal} / \mathrm{mol}\end{array}$} & \multirow[t]{4}{*}{-} & target 5' G G 3' \\
\hline & & & & & UGCUAUCCC CAUGU \\
\hline & & & & & ACGGUAGGG GUGCA \\
\hline & & & & & miRNA 3' U GGACC 5' \\
\hline \multirow[t]{4}{*}{ osa-miR1881 } & AAUGUUAUUGUAGCGUGGUGGUGU & 55 & $\begin{array}{l}-25.8 \\
\mathrm{kcal} / \mathrm{mol}\end{array}$ & - & $\begin{array}{l}\text { target 5' U GAG GGAG } \\
\text { CGAGUGUACAGUG A 3' }\end{array}$ \\
\hline & & & & & $\begin{array}{l}\text { CACC GCCACGC UACGAU } \\
\text { AACA }\end{array}$ \\
\hline & & & & & $\begin{array}{l}\text { GUGG UGGUGCG AUGUUA } \\
\text { UUGU }\end{array}$ \\
\hline & & & & & miRNA 3' U AA 5' \\
\hline bdi-miR5172 & UGAUCUACUAGCUCCUCGGCA & 57 & -25.9 & Seed match form $1-8$ allowing 1 & target 5' A CCAC GG C A 3' \\
\hline & & & रeai/latul & & CCGAGG GC AGUA GAUCG \\
\hline & & & & & GGCUCC CG UCAU CUAGU \\
\hline & & & & & miRNA 3' AC U A 5' \\
\hline gra-miR482 & UCUUUCCAAUUCCUCCCAUUCC & 26 & -25.7 & Seed match form $1-8$ allowing 1 & target 5' A C G 3' \\
\hline & & & Kedi/latol & Dit in & GGGAGGA UU GAAAGA \\
\hline & & & & & CCCUCCU AA CUUUCU \\
\hline & & & & & miRNA 3' CCUUA U C 5' \\
\hline osa-miR1430 & UGGUGAGCCUUCCUGGCUAAG & 98 & -27.2 & - & target $5^{\prime} \cup A \cup 3^{\prime}$ \\
\hline & & & & & GCUAGGGAG GCU GCC \\
\hline & & & & & CGGUCCUUC CGA UGG \\
\hline & & & & & miRNA 3' GAAU G U 5' \\
\hline pab-miR3698 & CUUGCAACUCUGCCUUGGCUUA & 60 & -25.1 & - & target 5' G C ACGAU U 3' \\
\hline & & & & & AGGCCA GCGGAGU CGAG \\
\hline & & & & & UUCGGU CGUCUCA GUUC \\
\hline & & & & & miRNA 3' A UC AC 5' \\
\hline
\end{tabular}




\begin{tabular}{|c|c|c|c|c|c|}
\hline $\begin{array}{l}\text { miRNA name } \\
\text { (miRBase) }\end{array}$ & miRNA sequence & $\begin{array}{l}\text { Binding } \\
\text { start } \\
\text { position }\end{array}$ & $\begin{array}{l}\mathrm{MFE} \\
\mathrm{kcal} / \mathrm{mol}\end{array}$ & Seed Type & Target/miRNA alignment \\
\hline \multirow[t]{4}{*}{${ }_{5 p}^{g m a-m i R 171 b-~}$} & \multirow[t]{4}{*}{ ACGGCGUGAUAUUGGUACGGCUC } & \multirow[t]{4}{*}{40} & \multirow[t]{4}{*}{$\begin{array}{l}-25.2 \\
\mathrm{kcal} / \mathrm{mol}\end{array}$} & \multirow[t]{4}{*}{-} & $\begin{array}{l}\text { target } 5^{\prime} \text { A ACCACAUUUUC } \\
\text { GGC G A } 3^{\prime}\end{array}$ \\
\hline & & & & & GAGCC ACCGA CACGC G \\
\hline & & & & & CUCGG UGGUU GUGCG C \\
\hline & & & & & miRNA 3' CA AUA G A 5' \\
\hline \multirow[t]{4}{*}{ pta-miR1310 } & \multirow[t]{4}{*}{ GGCAUCGGGGGCGUAACGCCCCU } & \multirow[t]{4}{*}{26} & \multirow[t]{4}{*}{$\begin{array}{l}-25.2 \\
\mathrm{kcal} / \mathrm{mol}\end{array}$} & \multirow[t]{4}{*}{-} & $\begin{array}{l}\text { target 5' A A AC AAAGA } \\
\text { ACCACAUUUUCA G A } 3^{\prime}\end{array}$ \\
\hline & & & & & GGG GG UUG GCC CCGA GCC \\
\hline & & & & & UCC CC AAU CGG GGCU CGG \\
\hline & & & & & miRNA 3' GC G G A 5' \\
\hline \multirow[t]{4}{*}{ ptc-miR473b } & \multirow[t]{4}{*}{ GCUCUCCCUCAGGGCUUCCA } & \multirow[t]{4}{*}{98} & \multirow{4}{*}{$\begin{array}{l}-25.8 \\
\mathrm{kcal} / \mathrm{mol}\end{array}$} & \multirow[t]{4}{*}{8 mer } & target 5' U U 3' \\
\hline & & & & & GCU AGGGAGAGC \\
\hline & & & & & CGG UCCCUCUCG \\
\hline & & & & & miRNA 3' ACCUU GAC 5' \\
\hline \multirow[t]{4}{*}{ ppt-miR1034 } & \multirow[t]{4}{*}{ UUACUUUGGCAGCGCUGUGCU } & \multirow[t]{4}{*}{84} & \multirow{4}{*}{$\begin{array}{l}-26.7 \\
\mathrm{kcal} / \mathrm{mol}\end{array}$} & \multirow[t]{4}{*}{-} & target 5' U AACAA A 3' \\
\hline & & & & & GUACAGUG UGCUAGGG \\
\hline & & & & & CGUGUCGC ACGGUUUC \\
\hline & & & & & miRNA 3' U G AUU 5' \\
\hline \multirow[t]{4}{*}{ gma-miR396e } & \multirow[t]{4}{*}{ UUCCACAGCUUUCUUGAACUGU } & \multirow[t]{4}{*}{86} & \multirow[t]{4}{*}{$\begin{array}{l}-25.8 \\
\mathrm{kcal} / \mathrm{mol}\end{array}$} & \multirow[t]{4}{*}{-} & $\begin{array}{l}\text { target 5' U GAACAAUGCUA } \\
\text { CCUAUA G } 3^{\prime}\end{array}$ \\
\hline & & & & & $\begin{array}{l}\text { ACAGU GGGAGAGCUG } \\
\text { UGGAA }\end{array}$ \\
\hline & & & & & UGUCA UUCUUUCGAC ACCUU \\
\hline & & & & & miRNA 3' AG 5' \\
\hline \multirow[t]{4}{*}{ osa-miR1424 } & AUGCACACUGAUGCUGAUUGU & 1 & -26.6 & $7 m e r-1 A$ & target 5' UUUA A 3' \\
\hline & & & & & CAAUC AUCAGUGUGUA \\
\hline & & & & & GUUAG UAGUCACACGU \\
\hline & & & & & miRNA 3' U UCG A 5' \\
\hline osa-miR1433 & UGGCAAGUCUCCUCGGCUACC & 98 & $\begin{array}{l}-25.3 \\
\text { kcal/mol }\end{array}$ & - & target 5' U A GC U 3' \\
\hline & & & & & GCU GGGAGA UGCC \\
\hline & & & & & CGG UCCUCU ACGG \\
\hline & & & & & miRNA 3' CCAU C GA U 5' \\
\hline cre-miR909.1 & UGCUGGUCAAACCGGUGGUGG & 43 & $\begin{array}{l}-25.2 \\
\mathrm{kcal} / \mathrm{mol}\end{array}$ & - & $\begin{array}{l}\underset{\mathrm{G}}{\operatorname{target}} 3^{\prime} \\
5^{\prime} \mathrm{G} \text { AUUUUCACCGA C }\end{array}$ \\
\hline & & & & & CCACCAC GGCCA GCG \\
\hline & & & & & GGUGGUG CUGGU CGU \\
\hline & & & & & miRNA 3' GCCAAA 5' \\
\hline gma-miR4389 & UCGGUCGGACCGAUCCAAUCGGAA & 24 & -25.7 & 7mer-A1 & target 5' A CCACG AGUA G 3' \\
\hline & & & & & CCGA GG CGG CGAUCGA \\
\hline & & & & & GGCU CC GCC GCUGGCU \\
\hline & & & & & miRNA 3' AA AA UA AG 5' \\
\hline mtr-miR398c & UGUGUUCUCAGGUCGCCCCUG & 24 & -25.5 & - & target 5' U A AA C 3' \\
\hline & & & & & UAGGG G GACUUGA GAGC CA \\
\hline & & & & & GUCCC C CUGGACU CUUG GU \\
\hline & & & & & miRNA 3' G U 5' \\
\hline
\end{tabular}




\begin{tabular}{|c|c|c|c|c|c|}
\hline $\begin{array}{l}\text { miRNA name } \\
\text { (miRBase) }\end{array}$ & miRNA sequence & $\begin{array}{l}\text { Binding } \\
\text { start } \\
\text { position }\end{array}$ & $\begin{array}{l}\mathrm{MFE} \\
\mathrm{kcal} / \mathrm{mol}\end{array}$ & Seed Type & Target/miRNA alignment \\
\hline \multirow[t]{4}{*}{ ppt-miR898a } & \multirow[t]{4}{*}{ UUGCUGUGCACUACUUAGUAC } & \multirow[t]{4}{*}{72} & \multirow{4}{*}{$\begin{array}{l}-25.5 \\
\mathrm{kcal} / \mathrm{mol}\end{array}$} & \multirow[t]{4}{*}{ 8mer } & target 5' A GAUCG A 3' \\
\hline & & & & & GUAC AGUGUACAGUGA \\
\hline & & & & & CAUG UCACGUGUCGUU \\
\hline & & & & & miRNA 3' AUUCA 5' \\
\hline \multirow[t]{4}{*}{ pab-miR482c } & \multirow[t]{4}{*}{ UCUUUCCUACUCCUCCCAUUCC } & \multirow[t]{4}{*}{26} & \multirow{4}{*}{$\begin{array}{l}-25.0 \\
\mathrm{kcal} / \mathrm{mol}\end{array}$} & \multirow[t]{4}{*}{ Seed + single mismatch } & target 5' A CUU G 3' \\
\hline & & & & & GGGAGGA GAAAGA \\
\hline & & & & & CCCUCCU CUUUCU \\
\hline & & & & & miRNA 3' CCUUA CAUC 5' \\
\hline \multirow[t]{4}{*}{ osa-miR5493 } & \multirow[t]{4}{*}{ AGCCGGGCUCGGUCGCGCGUG } & \multirow[t]{4}{*}{64} & \multirow{4}{*}{$\begin{array}{l}-27.9 \\
\mathrm{kcal} / \mathrm{mol}\end{array}$} & \multirow[t]{4}{*}{-} & target 5' C GAGUA GUA A G 3' \\
\hline & & & & & CACGCG CGAUCGAGU C GU \\
\hline & & & & & GUGCGC GCUGGCUCG G CG \\
\hline & & & & & miRNA 3' G C A 5' \\
\hline \multirow[t]{4}{*}{ osa-miR5149 } & \multirow[t]{4}{*}{ GAGGAGCUGUGACGAUUUGGGA } & \multirow[t]{4}{*}{161} & \multirow{4}{*}{$\begin{array}{l}-25.2 \\
\mathrm{kcal} / \mathrm{mol}\end{array}$} & \multirow[t]{4}{*}{8 mer } & target 5' C UGU UUA A 3' \\
\hline & & & & & CCCA GAUU AUAGCUUCUU \\
\hline & & & & & GGGU UUAG UGUCGAGGAG \\
\hline & & & & & miRNA 3' A CAG 5' \\
\hline \multirow[t]{4}{*}{ mtr-miR5205c } & \multirow[t]{4}{*}{ CUUAUAAUUAGGGACGGAGGUAGU } & \multirow[t]{4}{*}{108} & \multirow[t]{4}{*}{$\begin{array}{l}-26.8 \\
\mathrm{kcal} / \mathrm{mol}\end{array}$} & \multirow[t]{4}{*}{-} & $\begin{array}{l}\text { target } 5 \text { ' A AUA GAAGAG G A } \\
3^{\prime}\end{array}$ \\
\hline & & & & & $\begin{array}{l}\text { GCUGCCU UG CCCUAAU } \\
\text { UGUAA }\end{array}$ \\
\hline & & & & & $\begin{array}{l}\text { UGAUGGA GC GGGAUUA } \\
\text { AUAUU }\end{array}$ \\
\hline & & & & & miRNA 3' G A C 5' \\
\hline \multirow[t]{4}{*}{ osa-miR1879 } & GUGUUUGGUUUAGGGAUGAGGUGG & 43 & $\begin{array}{l}-25.3 \\
\mathrm{kcal} / \mathrm{mol}\end{array}$ & - & target 5' G A UUCA G C G 3' \\
\hline & & & & & $\begin{array}{l}\text { CCACC CAUU CC AGGCCA } \\
\text { GCG }\end{array}$ \\
\hline & & & & & $\begin{array}{l}\text { GGUGG GUAG GG UUUGGU } \\
\text { UGU }\end{array}$ \\
\hline & & & & & miRNA 3' A A U G 5' \\
\hline ptc-miR159e & CUUGGGGUGAAGGGAGCUCCU & 103 & $\begin{array}{l}-26.8 \\
\mathrm{kcal} / \mathrm{mol}\end{array}$ & 7 mer-8site & $\begin{array}{l}\text { target 5' G A G AUAUGGAAGA } \\
\cup 3^{\prime}\end{array}$ \\
\hline & & & & & GG GAGCU CCU GCCCUAA \\
\hline & & & & & UC CUCGA GGA UGGGGUU \\
\hline & & & & & miRNA 3' G AG C 5' \\
\hline pab-miR3704 & GGUCUAGGUGGAGUUGGAAAAA & 46 & -25.0 & - & target 5' A CAU G A 3' \\
\hline & & & & & CCA UUUCACC AGGCC \\
\hline & & & & & GGU GAGGUGG UCUGG \\
\hline & & & & & miRNA 3' AAAAA U A 5' \\
\hline osa-miR1433 & UGGCAAGUCUCCUCGGCUACC & 98 & -25.3 & - & target 5' U A GC U 3' \\
\hline & & & & & GCU GGGAGA UGCC \\
\hline & & & & & CGG UCCUCU ACGG \\
\hline & & & & & miRNA 3' CCAU C GA U 5' \\
\hline gma-miR4389 & UCGGUCGGACCGAUCCAAUCGGAA & 57 & -25.7 & $7 m e r-1 A$ & target 5' A CCACG AGUA G 3' \\
\hline & & & & & CCGA GG CGG CGAUCGA \\
\hline & & & & & GGCU CC GCC GCUGGCU \\
\hline & & & & & miRNA 3' AA AA UA AG 5' \\
\hline
\end{tabular}




\begin{tabular}{|c|c|c|c|c|c|}
\hline $\begin{array}{l}\text { miRNA name } \\
\text { (miRBase) }\end{array}$ & miRNA sequence & $\begin{array}{l}\text { Binding } \\
\text { start } \\
\text { position }\end{array}$ & $\begin{array}{l}\mathrm{MFE} \\
\mathrm{kcal} / \mathrm{mol}\end{array}$ & Seed Type & Target/miRNA alignment \\
\hline \multirow[t]{4}{*}{ osa-miR5493 } & AGCCGGGCUCGGUCGCGCGUG & 64 & $\begin{array}{l}-27.9 \\
\mathrm{kcal} / \mathrm{mol}\end{array}$ & - & target 5' C GAGUA GUA A G 3' \\
\hline & & & & & CACGCG CGAUCGAGU C GU \\
\hline & & & & & GUGCGC GCUGGCUCG G CG \\
\hline & & & & & miRNA 3' G C A 5' \\
\hline \multirow[t]{4}{*}{ aly-miR862-5p } & UCCAAUAGGUCUAGCAUGUGC & 84 & $\begin{array}{l}-25.4 \\
\mathrm{kcal} / \mathrm{mol}\end{array}$ & $\begin{array}{l}\text { Seed match form } 1-8 \text { allowing } 1 \\
\text { bit insertion seed match }\end{array}$ & $\begin{array}{l}\text { target 5' U GUGAACAA } \\
\text { GGAGAGCU A A } 3^{\prime}\end{array}$ \\
\hline & & & & & $\begin{array}{l}\text { GUACA UGCUAG GCCUAU } \\
\text { UGGA }\end{array}$ \\
\hline & & & & & $\begin{array}{l}\text { CGUGU ACGAUC UGGAUA } \\
\text { ACCU }\end{array}$ \\
\hline & & & & & miRNA 3' 5' \\
\hline \multirow[t]{4}{*}{$\begin{array}{l}\text { osa-miR2102- } \\
3 p\end{array}$} & CAUGGUGCCGGUUCCGGUGGCG & 62 & $\begin{array}{l}-27.6 \\
\mathrm{kcal} / \mathrm{mol}\end{array}$ & $\begin{array}{l}\text { Seed match form } 1-8 \text { allowing } 1 \\
\text { bit insertion seed match }\end{array}$ & $\begin{array}{l}\text { target } 5 ' \text { G G GUACG AGU A A } \\
3^{\prime}\end{array}$ \\
\hline & & & & & $\begin{array}{l}\text { GCCAC CGGA AUCG GUAC } \\
\text { GUG }\end{array}$ \\
\hline & & & & & $\begin{array}{l}\text { CGGUG GCCU UGGC CGUG } \\
\text { UAC }\end{array}$ \\
\hline & & & & & miRNA 3' G G 5' \\
\hline \multirow[t]{4}{*}{ osa-miR820a } & UCGGCCUCGUGGAUGGACCAG & 46 & -25.6 & - & target 5' A CAUU C A 3' \\
\hline & & & 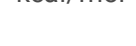 & & CCA UUCAC GAGGCC \\
\hline & & & & & GGU AGGUG CUCCGG \\
\hline & & & & & miRNA 3' GACCA CU 5' \\
\hline \multirow[t]{4}{*}{ gma-miR4379 } & UAGAGUGUAUACUGUGAGAGGCCU & 60 & -25.4 & - & target 5' G A A A G 3' \\
\hline & & & & & AGGCC CGCGG GUACG UC \\
\hline & & & & & UCCGG GUGUC UAUGU AG \\
\hline & & & & & miRNA 3' AGA A G AU 5' \\
\hline \multirow[t]{4}{*}{ gma-miR4375 } & UACCACUAGUGGUCGCGCCUGGCA & 62 & -26.3 & - & target 5' G C G GAUCG U 3' \\
\hline & & & & & GCCA GCG GA UAC AGUG \\
\hline & & & & & CGGU CGC CU GUG UCAC \\
\hline & & & & & miRNA 3' A C G G A CAU 5' \\
\hline \multirow[t]{4}{*}{ rgl-miR5140 } & GCUGGUGAAGAUUUGGUG & 44 & -25.7 & - & target 5' C C GA C 3' \\
\hline & & & & & CACCA AUUUUCACC GGC \\
\hline & & & & & GUGGU UAGAAGUGG UCG \\
\hline & & & & & miRNA 3' U 5' \\
\hline \multirow[t]{4}{*}{ cre-miR1144b } & UGGGUAGUGUGGCGGCAGGCAG & 97 & $\begin{array}{l}-25.9 \\
\mathrm{kcal} / \mathrm{mol}\end{array}$ & - & $\begin{array}{l}\text { target 5' A AGGGAGA U } \\
\text { GGAAGA U 3' }\end{array}$ \\
\hline & & & & & UGCU GCUGCC AUAU GCCC \\
\hline & & & & & ACGG CGGCGG UGUG UGGG \\
\hline & & & & & miRNA 3' G A A U 5' \\
\hline \multirow[t]{4}{*}{ aly-miR391 } & UUCGCAGGAGAGAUAGCGCCA & 153 & -25.0 & - & target $5^{\prime} \mathrm{A} A \cup 3^{\prime}$ \\
\hline & & & & & GUGCUAUC C CC UGUGA \\
\hline & & & & & CGCGAUAG G GG ACGCU \\
\hline & & & & & miRNA 3' AC A A U 5' \\
\hline
\end{tabular}




\begin{tabular}{|c|c|c|c|c|c|}
\hline $\begin{array}{l}\text { miRNA name } \\
\text { (miRBase) }\end{array}$ & miRNA sequence & $\begin{array}{l}\text { Binding } \\
\text { start } \\
\text { position }\end{array}$ & $\begin{array}{l}\mathrm{MFE} \\
\mathrm{kcal} / \mathrm{mol}\end{array}$ & Seed Type & Target/miRNA alignment \\
\hline \multirow[t]{4}{*}{ vvi-miR479 } & \multirow[t]{4}{*}{ UGUGGUAUUGGUUCGGCUCAUC } & \multirow[t]{4}{*}{40} & \multirow[t]{4}{*}{$\begin{array}{l}-25.4 \\
\mathrm{kcal} / \mathrm{mol}\end{array}$} & \multirow[t]{4}{*}{$\begin{array}{l}\text { Seed match form } 1-8 \text { allowing } 1 \\
\text { bit insertion seed match }\end{array}$} & $\begin{array}{l}\text { target } 5^{\prime} \text { A ACCACAUUUUC G C } \\
3^{\prime}\end{array}$ \\
\hline & & & & & GAGCC ACCGA GCCACG \\
\hline & & & & & CUCGG UGGUU UGGUGU \\
\hline & & & & & miRNA 3' CUA CU A 5' \\
\hline \multirow[t]{4}{*}{ osa-miR5531 } & \multirow[t]{4}{*}{ ACUGACUGCCUUGAGCUCCGGG } & \multirow[t]{4}{*}{66} & \multirow{4}{*}{$\begin{array}{l}-25.5 \\
\mathrm{kcal} / \mathrm{mol}\end{array}$} & \multirow[t]{4}{*}{ - } & target $5^{\prime}$ A G ACGA U G 3' \\
\hline & & & & & C CGGAGU UCGAG GUA CAGU \\
\hline & & & & & G GCCUCG AGUUC CGU GUCA \\
\hline & & & & & miRNA 3' G CA 5' \\
\hline \multirow[t]{4}{*}{ mtr-miR2659c } & \multirow[t]{4}{*}{ CCAUGGGUGCGACUUGGUAAG } & \multirow[t]{4}{*}{97} & \multirow{4}{*}{$\begin{array}{l}-25.3 \\
\mathrm{kcal} / \mathrm{mol}\end{array}$} & \multirow[t]{4}{*}{ - } & target 5' A GAGA UG UAU A 3' \\
\hline & & & & & UGCUAGG GC CC AUGG \\
\hline & & & & & AUGGUUC CG GG UACC \\
\hline & & & & & miRNA 3' GA AG UG 5' \\
\hline \multirow[t]{4}{*}{ ppt-miR898b } & \multirow[t]{4}{*}{ UUGCUGUGCACUACUUAGUAC } & \multirow[t]{4}{*}{72} & \multirow{4}{*}{$\begin{array}{l}-25.5 \\
\mathrm{kcal} / \mathrm{mol}\end{array}$} & \multirow[t]{4}{*}{8 mer } & target 5' A GAUCG A 3' \\
\hline & & & & & GUAC AGUGUACAGUGA \\
\hline & & & & & CAUG UCACGUGUCGUU \\
\hline & & & & & miRNA 3' AUUCA 5' \\
\hline \multirow[t]{4}{*}{ bdi-miR319b } & \multirow[t]{4}{*}{ UUGGACUGAAGGGUGCUCCCU } & \multirow[t]{4}{*}{25} & \multirow{4}{*}{$\begin{array}{l}-25.0 \\
\mathrm{kcal} / \mathrm{mol}\end{array}$} & \multirow[t]{4}{*}{-} & target 5' U G GAA AG C 3' \\
\hline & & & & & AGGGAG ACUU AG CCA \\
\hline & & & & & UCCCUC UGGG UC GGU \\
\hline & & & & & miRNA 3' G AAG A U 5' \\
\hline \multirow[t]{4}{*}{ osa-miR531 } & \multirow[t]{4}{*}{ CUCGCCGGGGCUGCGUGCCGCCAU } & \multirow[t]{4}{*}{61} & \multirow{4}{*}{$\begin{array}{l}-26.5 \\
\mathrm{kcal} / \mathrm{mol}\end{array}$} & \multirow[t]{4}{*}{-} & target 5' A AGUA AU U 3' \\
\hline & & & & & GGC CACGCGG CG CGAG \\
\hline & & & & & CCG GUGCGUC GC GCUC \\
\hline & & & & & miRNA $3^{\prime}$ UA CC GGG C $5^{\prime}$ \\
\hline
\end{tabular}

Searching for patterns of the target islands by the RNA22 tool by G: U wobbles allowed setting in seed region revealed eight putative miRNA/target interaction sites (Table 2). Herein, we illustrated the pvu-miR159a.2 interact with the 3'-UTR in the same position predicted by the RNAhybrid (position 106) by a canonical conservative adenine at opposite base one complete Watson-Crick pairing within the seed region and additional Watson-Crick pairing at 8 . Also, pta-miR1315 has the 6 mer-site conservation type interaction with the 3 '-UTR sequence at the binding position of 28 . However, sbi-miR5387b interacts by the 3'-UTR region at the 25 to 49 nucleotides throughout the canonical 7-mer-m8 site type. Interestingly, pta-miR1315 and sbi-miR5387b were detected using the RNA22 and RNA-hybrid tools as putative miRNAs targeting the 3'-UTR. While the detected interact positions are not the same. Next, using the STarMir tool, eight miRNA/mRNA conformation predicted based on the logistic prediction models developed with miRNA binding data from cross-linking immunoprecipitation (CLIP) studies (Fig. 1). The result indicative four canonical miRNA/mRNA interaction types consist of 8mer, 7 mer-m8, $6 \mathrm{mer}$, and offset-6mer (Table 3 ). Based on the results, pvu-miR159a.2 and sbi-miR5387b were predicted as the most effectively interacting miRNAs in targeting the 3 '-UTR sequence, not only by the RNA22 tool but also by the STarMir tool at the same position. The miRNAs prediction commonly by the different algorithms increases the chance of targeting the $3^{\prime}$-UTR in vitro to induce the virus degradation and translational repression. Therefore, they identified as a suitable plant miRNA candidate for antiviral miRNA-based therapies. 
Table 2

Characteristic plant miRNAs having target site in the 3-UTR section of COVID-19 genome identified by the RNA22 tool.

\begin{tabular}{|c|c|c|c|c|c|}
\hline miR Name & miRNA sequence & $\begin{array}{l}\text { leftmost position of } \\
\text { predicted target site }\end{array}$ & $\begin{array}{l}\text { folding energy } \\
\mathrm{Kcal} / \mathrm{mol}\end{array}$ & Target/miRNA hybrid & $\mathrm{p}$ value \\
\hline pvu-miR159a.2 & CUUCCAUAUCUGGGGAGCUUC & 106 & -21.20 & $\begin{array}{l}\text { AGAGCTGCCT-ATATGGAAG } \\
:||||||:|||||| \mid \\
\text { CTTCGAGGGGTCTATACCTTC-5p }\end{array}$ & $3.3 \mathrm{E}-1$ \\
\hline pta-miR1315 & UGGAGGCCUGUCAGGUUCCCA & 28 & -19.20 & $\begin{array}{l}\text { GGAGGACTTGAAAGAGCCACCA } \\
\text { |:I:||| I| I|| I|| } \\
\text { ACCCTTGGACTGTC-CGGAGGT-5p }\end{array}$ & $2.24 \mathrm{E}-1$ \\
\hline sbi-miR5387b & CGUGGCUCUGACCGGUGCUAAAGG & 25 & -16.60 & $\begin{array}{l}\text { TAGGGAGGACTTGAAAGAGCCACC } \\
\text { | ||: | ||||||| } \\
\text { GGAAATCGTGGCCAGTCTCGGTGC-5p }\end{array}$ & $2.24 \mathrm{E}-1$ \\
\hline osa-miR1430 & UGGUGAGCCUUCCUGGCUAAG & 39 & -13.12 & $\begin{array}{l}\text { AAGAGCCACCACATTTTCACCG } \\
\|\| \| \text { :||||: } \\
\text { GAATCGGT-CCTTCCGAGTGGT-5p }\end{array}$ & $2.24 \mathrm{E}-1$ \\
\hline osa-miR2925 & UGGCGGCCGCGGGCUUCGU & 27 & -12.10 & $\begin{array}{l}\text { GGGAGGACTTGAAAGAGCCACCA } \\
:|| / /|||||| \mid \\
\text { TGCTTC-GGGC-GC-CGGCGGT-5p }\end{array}$ & $2.24 \mathrm{E}-1$ \\
\hline pab-miR3704 & GGUCUAGGUGGAGUUGGAAAAA & 42 & -17.20 & $\begin{array}{l}\text { AGCCACCACATTTTCACCGAGGCC } \\
\text { || : :::||| ||:\| } \\
\text { AAAAAGGT-TGAGGTGGATCTGG-5p }\end{array}$ & $2.24 \mathrm{E}-1$ \\
\hline osa-miR1879 & GUGUUUGGUUUAGGGAUGAGGUGG & 47 & -17.10 & $\begin{array}{l}\text { CCACATTTTCACCGAGGCCACGCGG } \\
\text { ||| || || |/|| :|: } \\
\text { GGTGGAGTAG-GGATTTGGTTTGTG-5p }\end{array}$ & $2.24 \mathrm{E}-1$ \\
\hline cre-miR1144b & UGGGUAGUGUGGCGGCAGGCAG & 93 & -13.00 & $\begin{array}{l}\text { AACAATGCTAGGGAGAGCTGCCTA } \\
\|::\|: \|: \mid \\
\text { GACGGACGG-CGGTGTGATGGGT-5p }\end{array}$ & $3.3 \mathrm{E}-1$ \\
\hline
\end{tabular}

Table 3

Putative plant miRNAs target site in the 3-UTR section of COVID-19 genome and their characteristics predicted by the STarMir algo

\begin{tabular}{|c|c|c|c|c|c|c|c|c|c|c|c|c|c|}
\hline miRNA & $\begin{array}{l}\text { Site } \\
\text { Position }\end{array}$ & $\begin{array}{l}\text { Logit } \\
\text { Prob }\end{array}$ & Score & $\begin{array}{l}\text { Seed } \\
\text { Position }\end{array}$ & $\begin{array}{l}\text { Seed } \\
\text { Type* }\end{array}$ & $\begin{array}{l}\Delta \mathbf{G} \\
\text { hybrid }\end{array}$ & $\begin{array}{l}\Delta \mathbf{G} \\
\text { nuclear }^{*}\end{array}$ & $\begin{array}{l}\Delta G \\
\text { total }^{*}\end{array}$ & $\begin{array}{l}\text { Site } \\
\text { Access* }\end{array}$ & $\begin{array}{l}\text { Seed } \\
\text { Access* }\end{array}$ & $\begin{array}{l}\text { Upstream } \\
\text { Access } \\
\text { (15nt)* }\end{array}$ & $\begin{array}{l}\text { Downstream } \\
\text { Access } \\
\text { (10nt)* }\end{array}$ & $\begin{array}{l}\text { Upstre } \\
\text { AU } \\
\text { (30nt) }\end{array}$ \\
\hline $\begin{array}{l}\text { gma- } \\
\text { miR4390 }\end{array}$ & $58-78$ & 0.846 & 0.033 & $71-77$ & 8 mer & -29.700 & -1.373 & -16.637 & 0.449 & 0.384 & 0.340 & 0.530 & 0.533 \\
\hline $\begin{array}{l}\text { pvu- } \\
\text { miR159a.2 }\end{array}$ & $\begin{array}{l}107- \\
124\end{array}$ & 0.761 & 0.022 & $\begin{array}{l}117- \\
123\end{array}$ & $\begin{array}{l}\text { 7mer- } \\
\text { m8 }\end{array}$ & -28.300 & -4.129 & -18.708 & 0.453 & 0.484 & 0.592 & 0.249 & 0.533 \\
\hline $\begin{array}{l}\text { sbi- } \\
\text { miR5387b }\end{array}$ & $30-47$ & 0.689 & 0.035 & $41-47$ & $\begin{array}{l}\text { 7mer- } \\
\mathrm{m} 8\end{array}$ & -25.400 & 0 & -15.911 & 0.420 & 0.221 & 0.393 & 0.355 & 0.655 \\
\hline $\begin{array}{l}\text { ptc- } \\
\text { miR473b }\end{array}$ & $99-110$ & 0.656 & 0.024 & $\begin{array}{l}103- \\
109\end{array}$ & $\begin{array}{l}\text { 7mer- } \\
\mathrm{m} 8\end{array}$ & -25.800 & -7.675 & -18.194 & 0.518 & 0.642 & 0.534 & 0.472 & 0.533 \\
\hline $\begin{array}{l}\text { mtr- } \\
\text { miR2659a }\end{array}$ & $\begin{array}{l}148- \\
167\end{array}$ & 0.656 & 0.021 & $\begin{array}{l}162- \\
167\end{array}$ & 6 mer & -18 & -5.364 & -11.954 & 0.613 & 0.752 & 0.440 & 0.424 & 0.700 \\
\hline $\begin{array}{l}\text { osa- } \\
\text { miR1881 }\end{array}$ & $10-25$ & 0.590 & 0.041 & $19-24$ & 6 mer & -15.200 & -1.862 & -8.188 & 0.516 & 0.419 & 0.473 & 0.259 & 0.778 \\
\hline $\begin{array}{l}\text { osa- } \\
\text { miR820a }\end{array}$ & $47-65$ & 0.548 & 0.017 & $60-65$ & $\begin{array}{l}\text { offset- } \\
6 \mathrm{mer}\end{array}$ & -25.600 & -0.891 & -14.734 & 0.406 & 0.345 & 0.403 & 0.412 & 0.567 \\
\hline $\begin{array}{l}\text { osa- } \\
\text { miR2930 }\end{array}$ & $\begin{array}{l}112- \\
126\end{array}$ & 0.531 & 0.026 & $\begin{array}{l}121- \\
126\end{array}$ & $\begin{array}{l}\text { offset- } \\
6 \mathrm{mer}\end{array}$ & -15.900 & -1.319 & -7.850 & 0.473 & 0.488 & 0.549 & 0.172 & 0.533 \\
\hline
\end{tabular}




\section{Discussion}

The severe acute respiratory syndrome coronavirus 2 (SARS-CoV-2) is a positive-sense single-stranded RNA (+ ssRNA) virus with a single linear RNA segment. It causes coronavirus disease (COVID-19). Coronaviruses have a cytoplasmic RNA-based replication cycle (de-Boon et al. 2010; V'kovski et al. 2021). Their genome is used directly as a template for the generation of viral protein and non-protein by-products. By-products are related to virus-induced intracellular double-membrane vesicles (de-Boon et al. 2010; V'kovski et al. 2021) to isolate the virion from the host cell. Therefore, the RNA replication process in coronaviruses occurs in the protective environment (Van Hemert et al. 2008). However, the exchange of ribonucleotides and the by-products through such a double-membrane vesicle remains unknown. It hypothesized that the proteinaceous membrane pore to the cytoplasm might provide an opening connection to the cytoplasm (van Hemert et al. 2008). RNA viruses, including coronaviruses, can generate viral-specific and, or host-analogs miRNAs in their genomes regulating host gene expression network and, or viral genes, implicating in the viral cycle and the pathogenic properties of the virus (Cullen 2011; Kincaid and Sullivan 2012; Li and Zou 2019). However, there have been several documents that viral infection can affect the host MIR expression profile (Skalsky and Cullen 2010; Duan et al. 2020). They can manipulate the host miRNAs, escape an antiviral response. This condition creates a more favorable intracellular microenvironment for viral replication, infectivity, and pathogenesis (Umbach and Cullen 2009; Bruscella et al. 2017). In this regard, many publications have reported that host miRNA binding to the viral genome enhances its stability and translation (Ojha et al. 2016: Trobaugh and Klimstra 2017; Bernier and Sagan 2018; Erika et al. 2018). However, some host miRNAs can target the viral genome carry out antiviral activity (Mahajan et al. 2009; Russo and Potenza 2011; Hum et al. 2021). Based on recent shreds of proof, direct physical interaction of viral genome by host miRNA(s) is a more common biological aspect than anticipate (Girardi et al. 2018). Direct targeting viral genes and, or genome by the host cell miRNA probably suggests playing a chief role in determining which cells can become infected (tissue tropism) by a given virus (Gottwein and Cullen 2008; Girardi et al. 2018). However, for many of such interactions, its functional role remains to be fully determined. When the target site(s) are present by the infecting virus, viral replication/translation regulation by direct host miRNA/viral RNA interaction(s), resulting in positive regulation of the viral cycle. Although, it remains limited due to the high mutation rate of RNA viruses unless there is a forceful selective pressure to maintain the miRNA binding sites within the viral genome in the virus progeny throughout evolutionary history (Girardi et al. 2018).

As reported in many studies, exogenous miRNAs efficacies are similar to endogenous miRNAs (Alvarez et al., 2006; Schwab et al. 2006; Nielsen et al. 2007). miRNAs are neither immunogenic and nor protein-coding sequences. It has no toxicity or simulation of undesired autoimmune response or other side effects, such as the knockdown of non-target mRNA(s), which has a pivotal biological function. Therefore, the design of anti-viral miRNA based to target the viral 3'UTR and has too gene-specificity to block the expression of the genes associated with the same seed binding site can inhibit viral translation and replication and have valuable therapeutic potential.

The translation is a multi-step process including initiation, elongation, and termination that beginning and continuing with the association of ribosomal subunits. In cap-dependent translation, poly-A tail plays a critical role in protecting the mRNA from degradation and leading to an effective translation by interacting with cytoplasmic poly-A binding protein forming a circular structure (Poulin et al. 2000). Translation of coronavirus is cap-depended (Cencic et al. 2011). The miRNA loaded in RISC can trigger the virus RNA deadenylation leading to decapping, and in the initiation phase, inhibit cap-depended translation. Without the 3'-polyA cap structure, the viral RNA fails to assume the circular conformation and translation process is depressed and ultimately degraded by the cytoplasmic 5'-to-3' exoribonucleases like XRN1(Nagarajan et al. 2013). However, deadenylation and translation repression can function independently. miRNAs that target the $3^{\prime}$-UTR of the viral genome can repress the translation before the deadenylation step occurs. However, the extension of the repression on deadenylated mRNA seems to be higher than the mRNA containing the poly-A tail.

Recent studies strongly support the notion that plant-derived miRNAs have the main role in the repression or inhibition of mammalian gene expression (Mlotshwa et al. 2015; Li et al. 2018; Dávalos et al. 2021). The analysis presented here provides supporting evidence that several plant miRNAs can theoretically interact with the COVID-19 genome at 3'-UTR region in a sequence-specific manner. Different algorithms collect their data sets from diverse sources. Therefore, their predictions are distinct due to employing varied rule(s) for target prediction resulting in a different list of targets, many of which are presumed to be false. In the meantime, pvu-miR159a.2 and sbi-miR5387b that all the employed algorithms highlight as potential miRNAs in targeting the viral genome. Therefore, they have the most probability of representing the most effectively interacting plant miRNAs with the 3'-UTR sequence of the COVID-19 genome. sbi-miR5387b have been identified in sweet sorghum (Zhang et al. 2011) and at least in one another monocot plant species (Aegilops tauschii; Akpinar and Budak 2016). The plant MIR159 family is one of the well-conserved predominant plant microRNA families. Its isoforms (differ from one another no more than four nucleotides) are highly abundant in flowering plants (Hajieghrari and Farrokhi 2020). The miR159 family members interact with the highly conserved R2R3 MYB transcription factor gene called GAMYB in the well-conserved binding site in land plant species (Millar et al. 2019). Pvu-miR159a.2 is the MIR159 family member, which has the interaction potential of the COVID-19 genome at the 3'-UTR region by the maximum free energy of more than 25 $\mathrm{kcal} / \mathrm{mol}$. Pvu-miR159a.2 is detected and characterized experimentally from common bean (Phaseolus vulgaris) when analyzing the different organ samples, including seed (Contreras-Cubas et al. 2012). In common bean developing seeds, pvu-miR159a.2 is most abundant. It showed that pvu-miR159a. 2 is methylated directly by HUA-ENHANCER 1 (HEN1), which modifies its 3' end. It is necessary for its stability. Several recent pieces of research indicated that 2'-0methylation of the plant mature miRNAs duplex on 3' terminal ribose (Zhao et al. 2012). It makes the duplex resistant to oxidation and high-temperature, processing like boiling and cocking allow them to take up by the gastrointestinal epithelial cells through dietary intake, influencing gene expression in mammals, including humans (Li et al. 2018). In this regard, several previous studies demonstrating the taking up diet-derived miRNAs in dietary material through gastrointestinal epithelial cells (Witwer and Zhang 2017; Li et al. 2018). They are packaging into micro vesicles or exosomes or incorporating into the proteins. Such a situation shelter it from degradation and by the entrance in the circulation delivered to the recipient cells sufficiently (for more details see Li et al. 2018). However, they may be filtered at the kidney and get out before being delivered to the recipient organ/cell. Plant-originated miRNAs can employ mammalian AGO2 protein to load into the RISC effector complex repressing the translation/degradation of the cell mRNA and, or viral translation/replication. Also, it is now clear that in mammals' consumers, orally-administrated synthetic/artificial 2'-0-methylated plant miRNAs duplex can take up at a sufficient level to exert its physiological impact (Chin et al. 2016). A notable case is using the synthetic form of miR159 as a dietary supplement in treating breast cancer by

Page $13 / 17$ 
targeting Transcription Factor 7 (TCF7) in mice (Chin et al. 2016). The body cell-produced exosomes are great potential in encapsulating synthetic/artificial 2'O-methylated plant miRNAs. It can protect the miRNA structure from RNase enzymatic degradation and delivered it to the target organ/cell.

However, our study evaluated the plant microRNAs in targeting the 3'-UTR sequence of the virus genome by the bioinformatics approach. It is worthy to note that common bean-derived pvu-miR159a.2 is a natural RNA molecule. Accumulating evidence suggested that it takes up common bean dietary material from both raw and cooked foods. Therefore, it may diffuse in the human body/cells without any side effect in vivo and can induce COVID-19 genome translation/replication in the affected cells, preventing more host cell infection. An applying concept emerging from this study is that common bean adding to human's diet mainly in the patient one is highly recommend. Therefore, it may have a good effect on the COVID-19 infected patient with severe condition with minimal off-target effects and more likely is a benefit for personal health. Also, it may be possible that pvu-miR159a.2 and the other plant-originated miRNAs, which can efficiently interact with the viral genome, may be generated artificially in the 3' end 2'-0-methylated duplex form and packing into exosome (or other vesicles). Then, it can deliver to the blood or aerosolized for delivery into the respiratory tract for suppressing the viral infection and, or cell antiviral responses in COVID-19 respiratory infection. It may have several benefits over traditional vaccines. However, such alternative/novel therapeutics require experimental validation in vitro and in vivo. We hope it urgently consider and examine to prevent the disease progression.

\section{Declarations}

\section{FUNDING}

This work has been supported by Jahrom University, Iran in Grant Code: 103/16133.

\section{CONFLICTS OF INTEREST/COMPETING INTERESTS}

The authors declare that this article content has no conflict of interest.

\section{AVAILABILITY OF DATA AND MATERIAL}

Not applicable

CODE AVAILABILITY

Not applicable

\section{AUTHORS' CONTRIBUTIONS}

The data analysis and preparation of the first draft was carried out by B.H and S.R-K checked the data and edited the manuscript.

ETHICS APPROVAL

Not applicable

CONSENT TO PARTICIPATE

Not applicable

CONSENT FOR PUBLICATION

Not applicable

\section{References}

Abu-Izneid A, Al-Hajri N, Ibrahim AM et al (2021) Micro-RNAs in the regulation of immune response against SARS CoV-2 and other viral infections. J Adv Res 30:133-145. Doi:10.1016/j.jare.2020.11.013.

Akpinar BA, Bukak H (2016) Dissecting miRNAs in wheat D genome progenitor, Aegilops tauschii. Front. Plant Sci 7:606. Doi:10.3389/fpls.2016.00606

Alvarez JP, Pekker I, Goldshmidt A et al (2006) Endogenous and synthetic microRNAs stimulate simultaneous, efficient, and localized regulation of multiple targets in diverse species. Plant Cell 18(5):1134-1151. Doi:10.1105/tpc.105.040725

Barbu MG, Condrat CE, Thompson DC et al (2020) MicroRNA Involvement in Signaling Pathways During Viral Infection. Front Cell Dev Biol 8:143. Doi:10.3389/fcell.2020.00143

Bernier A, Sagan SM (2018) The diverse roles of microRNAs at the host $\$ virus interface. Viruses. 2018;10(8):440. Doi:10.3390/v10080440

Bruscella P, Bottini S, Baudesson C et al (2017) Viruses and miRNAs: More Friends than Foes. Front Microbiol 8:824. Doi:10.3389/fmicb.2017.00824

Canatan D (2020). The impact of microRNAs (miRNAs) on the genotype of coronaviruses. Acta Biomed 91(2):195-198. 
Catalanotto C, Cogoni C, Zardo G (2016) MicroRNA in control of gene expression: an overview of nuclear functions. Int J Mol Sci 17(10):1712. Doi:10.3390/ijms17101712

Cencic R, Desforges M, Hall DR et al (2011) Blocking elF4E-elF4G interaction as a strategy to impair coronavirus replication. J Virol 85(13):6381-6389. Doi:10.1128/JVI.00078-11

Chin A, Fong M, Somlo G et al (2016) Cross-kingdom inhibition of breast cancer growth by plant miR159. Cell Res 26: 217-228. Doi:10.1038/cr.2016.13

Contreras-Cubas C, Rabanal FA, Arenas-Huertero C et al (2012) The Phaseolus vulgaris miR159a precursor encodes a second differentially expressed microRNA. Plant Mol Biol. 80(1):103-15. Doi: 10.1007/s11103-011-9847-0.

Dávalos A, Pinilla L, de las Hazas MCL et al (2021) Dietary microRNAs and cancer: A new therapeutic approach? Seminars in Cancer Biology 73:19-29. Doi:10.1016/j.semcancer.2020.10.006.

De-Boon JA, Diaz A, Ahlquist P (2010) Cytoplasmic viral replication complexes. Cell Host and Microbe 8:77-85.

Duan X, Wang L, Sun G et al (2020) Understanding the cross-talk between host and virus in poultry from the perspectives of microRNA. Poultry Science 99(4):1838-1846. Doi:10.1016/j.psj.2019.11.053.

Erika G, Paula L, Sébastien P (2018) On the importance of host microRNAs during viral infection.F rontiers in Genetics 9:439. Doi:10.3389/fgene.2018.00439

Farrokhi N, Hajieghrari B (2020) Chronicles of dolos and apate in plant microRNAs. Biologia 75 (12): 2465-2465.

Girardi E, Lopez P, Pfeffer S (2018) On the importance of host microRNAs during viral infection. Front Genet 9:439. Doi: 10.3389/fgene.2018.00439

Gottwein E, Cullen BR (2008) Viral and cellular microRNAs as determinants of viral pathogenesis and immunity. Cell Host Microb 3(6):375-387.

Doi:10.1016/j.chom.2008.05.002

Ha M, Kim V (2014) Regulation of microRNA biogenesis. Nat Rev Mol Cell Biol 15, 509-524. Doi: 10.1038/nrm3838

Hajieghrari B, Farrokhi N (2021). Investigation on the conserved MicroRNA genes in higher plants. Plant Molecular Biology Reporter 39(1):10-23.

Doi:10.1007/s11105-020-01228-9

Hajieghrari B, Farrokhi N, Goliaei B, Kavousi K (2017) Computational Identification of MicroRNAs and Their Transcript Target(s) in Field Mustard (Brassica rapa L.). Iran J Biotechnol 15(1):22-32. Doi:10.15171/ijb.1390

Hajieghrari B, Farrokhi N, Goliaei B, Kavousi K (2019) In silico identification of conserved miRNAs from Physcomitrella patens ESTs and their target characterization. Current Bioinformatics 14 (1), 33-42.

Hum C, Loiselle J, Ahmed N et al (2021) MicroRNA mimics or inhibitors as antiviral therapeutic approaches against COVID-19. Drugs 81, 517-531. Doi: $10.1007 /$ s40265-021-01474-5

Ingle H, Kumar S, Raut AA et al (2015) The microRNA miR-485 targets host and influenza virus transcripts to regulate antiviral immunity and restrict viral replication. Sci Signal 8(406):ra126. Doi: 10.1126/scisignal.aab3183.

Ji L, Chen X (2012) Regulation of small RNA stability: methylation and beyond. Cell Res 22:624-636.

Jopling CL, Yi M, Lancaster AM et al (2005) Modulation of hepatitis C virus RNA abundance by a liver-specific microRNA. Science 309:1577-1581.

Kehl T, Backes C, Kern F et al (2017) About miRNAs, miRNA seeds, target genes and target pathways. Oncotarget 8(63):107167-107175.

Doi:10.18632/oncotarget.22363

Khongnomnan K, Makkoch J, Poomipak W et al (2015) Human miR-3145 inhibits influenza A viruses replication by targeting and silencing viral PB1 gene. Exp Biol Med (Maywood) 240(12):1630-1639. Doi: 10.1177/1535370215589051

Krüger J, Rehmsmeier M (2006) RNAhybrid: microRNA target prediction easy, fast and flexible. Nucleic Acids Res 34(Web Server issue):W451-4. Doi: $10.1093 / \mathrm{nar} / \mathrm{gkl} 243$.

Lecellier CH, Dunoyer P, Arar K et al (2005) A cellular microRNA mediates antiviral defense in human cells. Science 308:557-560.

Li Z, Xu R, Li N (2018) MicroRNAs from plants to animals, do they define a new messenger for communication? Nutr Metab (Lond) 15:68.

Doi:10.1186/s12986-018-0305-8

Liang H, Banerjee N, Ivanov I et al (2013) New role for microRNAs in cross-species communication. RNA Biol 10:367-370.

Mahajan VS, Drake A, Chen J (2009) Virus-specific host miRNAs: antiviral defenses or promoters of persistent infection? Trends Immunol 30(1):1-7. Doi:10.1016/j.it.2008.08.009

Millar AA, Lohe A, Wong G (2019) Biology and function of miR159 in plants. Plants 8:255. Doi: 10.3390/plants8080255

Page $15 / 17$ 
Miranda KC, Huynh T, Tay Y et al (2006) A pattern-based method for the identification of microRNA binding sites and their corresponding heteroduplexes. Cell 126(6):1203-1217. Doi:10.1016/j.cell.2006.07.031.

Mlotshwa S, Pruss GJ, MacArthur JL et al (2015) A novel chemo preventive strategy based on therapeutic microRNAs produced in plants. Cell Res 25(4):5214.

Nagarajan VK, Jones Cl, Newbury SF, Green PJ (2013) XRN 5' $\rightarrow 3^{\prime}$ exoribonucleases: structure, mechanisms and functions. Biochim Biophys Acta 1829(67):590-603. Doi:10.1016/j.bbagrm.2013.03.005

Nguyen TH, Liu X, Su ZZ et al (2018) Potential role of microRNAs in the regulation of antiviral responses to influenza infection. Front Immunol 9:1541. Doi:10.3389/fimmu.2018.01541

Nielsen CB, Shomron N, Sandberg R, et al (2007) Determinants of targeting by endogenous and exogenous microRNAs and siRNAs. RNA13(11):1894-1910. Doi:10.1261/rna.768207

O'Brien J, Hayder H, Zayed Y, Peng C (2018) Overview of microRNA biogenesis, mechanisms of actions, and circulation. Front Endocrinol 9:402. Doi: $10.3389 /$ fendo.2018.00402

Ojha CR, Rodriguez M, Dever SM et al (2016) Mammalian microRNA: an important modulator of host-pathogen interactions in human viral infections. J Biomed Sci 23, 74. Doi:10.1186/s12929-016-0292-x

Pal M, Berhanu G, Desalegn C, Kandi V (2020) Severe Acute Respiratory Syndrome Coronavirus-2 (SARS-CoV-2): An Update Cureus 12(3):e7423.

Doi: $10.7759 /$ cureus. 7423

Poulin F, Sonenberg N (2000) Mechanism of Translation Initiation in Eukaryotes. In: Madame Curie Bioscience Database [Internet]. Austin (TX): Landes Bioscience 2000-2013. Available from: https://www.ncbi.nlm.nih.gov/books/NBK6597/

Rennie W, Liu C, Steven C et al (2014) CarmackSTarMir: a web server for prediction of microRNA binding sites. Nucleic Acids Res 42: W114-W118. Doi: $10.1093 /$ nar/gku376

Russo A, Potenza N (2011) Antiviral effects of human microRNAs and conservation of their target sites. FEBS Letters 585(16):2551-2555.

Doi:10.1016/j.febslet.2011.07.015.

Samad AFA, Kamaroddin MF, Sajad M (2020) Cross-kingdom regulation by plant microRNAs provides novel insight into gene regulation. Adv Nutr 00:1-15. Doi: 10.1093/advances/nmaa095.

Schwab R, Ossowski S, Riester M et al (2006) Highly Specific Gene Silencing by Artificial MicroRNAs in Arabidopsis. The Plant Cell 18(5):1121-1133. Doi:10.1105/tpc.105.039834

Shimakami T, Yamane D, Jangra RK et al (2012) Stabilization of hepatitis C virus RNA by an Ago2-miR-122 complex. Proc Natl Acad Sci U S A 17;109(3):9416. Doi: $10.1073 /$ pnas. 1112263109 .

Skalsky RL, Cullen BR (2010) Viruses, microRNAs, and host interactions. Annu Rev Microbiol 64:123-141. Doi:10.1146/annurev.micro.112408.134243

Song L, Liu H, Gao S et al (2010) Cellular microRNAs inhibit replication of the H1N1 influenza A virus in infected cells. J Virol 84(17):8849-60. Doi: 10.1128/JVI.00456-10.

Steinkraus BR, Toegel M, Fulga TA (2016) Tiny giants of gene regulation: experimental strategies for microRNA functional studies. WIREs Dev Biol 5:311-362. Doi: $10.1002 /$ wdev.223

Trobaugh DW, Klimstra WB (2017) MicroRNA regulation of RNA virus replication and pathogenesis. Trends Mol Med 23(1): 80-93. Doi: 10.1016/j.molmed.2016.11.003

Umbach JL, Cullen BR (2009) The role of RNAi and microRNAs in animal virus replication and antiviral immunity. Genes Dev 23(10):1151-64. Doi: $10.1101 / \operatorname{gad} .1793309$

V'kovski P, Kratzel A, Steiner S et al (2021) Coronavirus biology and replication: implications for SARS-CoV-2. Nat Rev Microbiol 19, 155-170. Doi:10.1038/s41579-020-00468-6

Van Hemert MJ, Van den Worm SH, Knoops K et al (2008) SARS-coronavirus replication/transcription complexes are membrane-protected and need a host factor for activity in vitro. PLoS Pathog 4, e1000054

Vaucheret H, Chupeau Y (2012) Ingested plant miRNA regulate gene expression in animals. Cell Res 22(1):3-5.

Wahid F, Shehzad A, Khan T, Kim YY (2010) MicroRNAs: Synthesis, mechanism, function, and recent clinical trials, Biochimica et Biophysica Acta (BBA) Molecular Cell Research 1803(11):1231-1243.

Wang W, Liu D, Zhang X et al (2018) Plant microRNAs in cross-kingdom regulation of gene expression. Int J Mol Sci 19:2007 
Witkos TM, Koscianska E, Krzyzosiak WJ (2011) Practical Aspects of microRNA Target Prediction. Curr Mol Med 11(2):93-109.

Doi:10.2174/156652411794859250

Witwer KW, Zhang CY (2017) Diet-derived microRNAs: unicorn or silver bullet? Genes Nutr 12, 15. Doi:10.1186/s12263-017-0564-4

Zhang L, Hou D, Chen X et al (2012) Exogenous plant MIR 168a specifically targets mammalian LDLRAPI: evidence of cross-kingdom regulation by microRNA. Cell Res 22:107-126.

Zhang L, Zheng Y, Jagadeeswaran G et al (2011) Identification and temporal expression analysis of conserved and novel microRNAs in Sorghum. Genomics 98:460-468.

Zhao Y, Mo B, Chen X (2012) Mechanisms that impact microRNA stability in plants. RNA Biol 9(10):1218-1223. Doi:10.4161/rna.22034

Zheng Z, Ke X, Wang M et al (2013) Human microRNA hsa-miR-296-5p suppresses enterovirus 71 replication by targeting the viral genome. J Virol 87: 56455656. Doi: $10.1128 / J V I .02655-12$

Zhou Z, Li X, Liu J, et al (2015) Honeysuckle-encoded atypical microRNA2911 directly targets influenza A viruses. Cell Res 25:39-49.

\section{Figures}

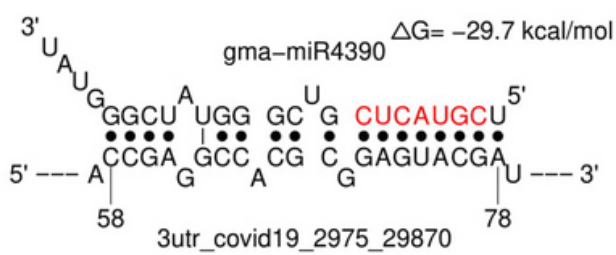

3utr_covid19_2975_29870

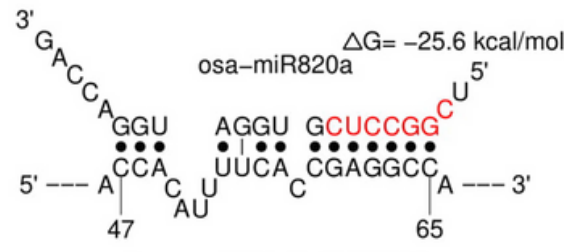

3utr_covid19_2975_29870

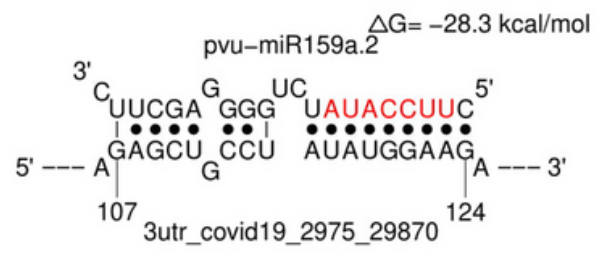

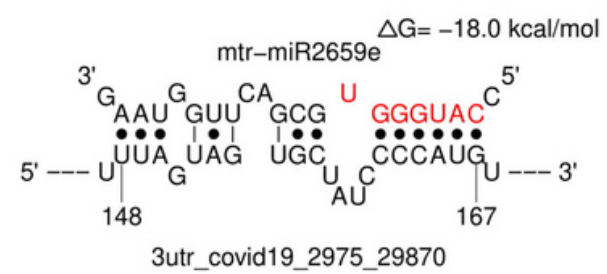

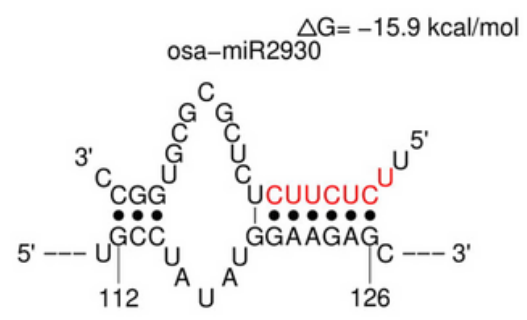

3utr_covid19_2975_29870
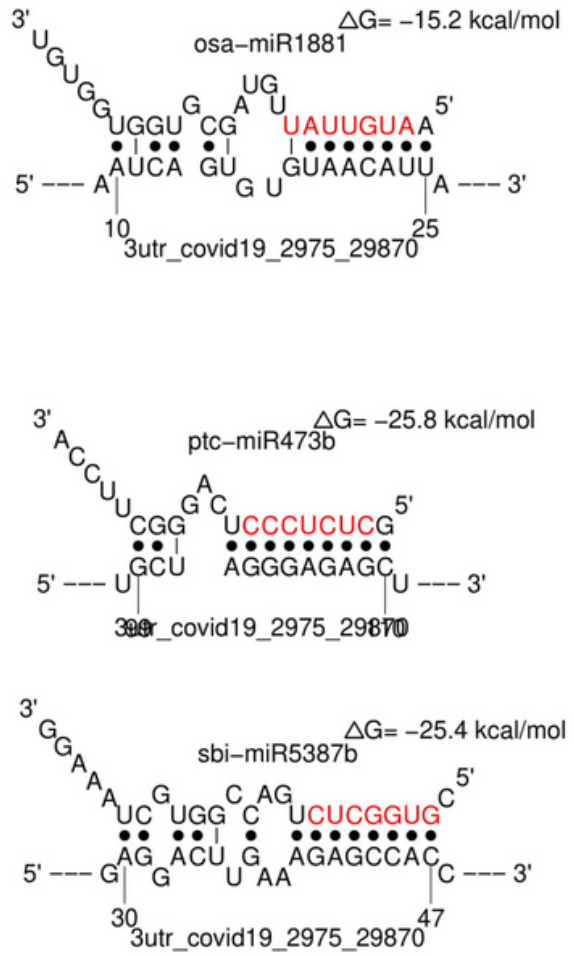

\section{Figure 1}

STarMir algorithm predicted plant miRNA-COVID-19 interaction patterns. 